\title{
Novel Technique for the Estimation of Shear Stress Amplitude under Completely Reversed Cyclic Shear Strain
}

\author{
Abdul Kareem F. Hassan*, Azzam D. Hassan \\ College of Engineering, Basrah University, Iraq
}

Copyright $(\mathrm{C} 2016$ by authors, all rights reserved. Authors agree that this article remains permanently open access under the terms of the Creative Commons Attribution License 4.0 International License

\begin{abstract}
Since it is easy to measure the applied torque, an empirical equation to predict the generated shear stress amplitude from the applied cyclic torque (under a low cyclic fatigue) has been carried out in this investigation. The equation has been expressed for a Brass material with a frequency of $375 \mathrm{rpm}$. The conducted tests in this investigation was completely reversed based on strain at $250^{\circ} \mathrm{C}$ whereas the shear strain amplitude, number of cycles to failure, and the maximum cyclic applied torque have been recorded during the tests. A fabricated rig has been used to conduct the experimental fatigue test at high temperature. The fatigue cyclic coefficients were estimated by applying the best fit equation for the recorded data. Ramberg-Osgood coefficients were found by substituting the fatigue cyclic coefficients in the relations that given by McClaflin and Fatemi. The empirical equation to predict the value of the shear stress amplitude was found for each value of the maximum torque that exposure to the material. The best fit of the shear stress amplitude that results from Ramberg-Osgood equation and with the recorded cyclic torque has been estimated. The effect of the temperature was also taken in the consideration on the fatigue strength which clearly observed that the high temperature lead to reduce the fatigue strength.
\end{abstract}

Keywords Brass, Shear Stress Amplitude, Cyclic Shear Strain, Torsional Fatigue

\section{Introduction}

The cyclic torque that applied on the material is easy to be measured and since the relationship between the stress and strain is hard to be found, Therefore in this research has been find a relationship that predict stress resulting from the applied cyclic torque. Fatigue is a widespread problem in industrial materials. It limits the useful life of structural components, and engineering failures can be traced to fatigue [1].
Fluctuating stresses of construction units generate specific changes and fatigue phenomena. If these stresses are big enough they may locally cause the plastic strains in such a unit. During fatigue life calculations of the construction units containing locally areas of the plastic - elastic strains there are used material data defined in the low-cycle fatigue area [2]. Plastic strain caused increase of the dislocation density in the $\alpha$ phase during fatigue tests for brass that led to its hardening, and in case of initiation and cracking development those processes appeared with bigger loadings [3].

The cyclic torsional fatigue life of a brass is often measured as the number of cycles to fracture, $\mathrm{N}_{\mathrm{f}}$. This, however, is in some sense a misleading definition because the final rupture may involve 5 to $10 \%$ of $\mathrm{N}_{\mathrm{f}}$ [4], therefore, a correlate the fatigue life with the number of cycles required to cause a rapid decrease in stress amplitude.

Experimental tests were carried out at a constant angular speed that imposed a constant shear strain rate to the test specimen, an encoder obtains the torsion angle and the torque is measured by a load cell [5]. The torsion tests have been performed on annealed materials such as 1020 steel, brass, pure copper and pure aluminum. During testing, the torque and twist angle values were continually recorded and the von Mises effective stress and effective strain were calculated using equations to predict the behavior of brass.

Some authors were found an empirical relation also for the Brass material that related different factors, an empirical relation which related between the fatigue strength and the hardness has been carried out through many tests for a brass[6]. Hardness has a significant effect on the fatigue strength at high temperature

Investigation about the endurance limit of aluminum, brass, and mild steel had been done[7]. The endurance limit of the specimens have been determined by testing under different loads on the fatigue testing machine and the life cycles of each specimens has been taken after crack occur on the specimen. 
The aim of this investigation is to find an empirical equation that relates the shear stress amplitude with a maximum cyclic torque applied to the specimen. The prediction equation gives the shear stress amplitude at $250^{\circ} \mathrm{C}$ which can then estimate the number of cycles to failure from the S-N curve.

\section{Experimental Procedure}

A cyclic torsional test has been conducted for a brass specimens with chemical composition listed in the Table 1 using a fatigue torsional rig (based on strain) with a controller of temperature. The Rig used in this work has been constructed and fabricated to perform a combined action of creep and torsional fatigue at room and high temperature. The shape of the present rig has been envisaged through the references to many previous studies and attempts $[8,9,10]$. The construction of the rig has been concluded following the minimization or avoidance of errors taking place in its constituent parts. In addition, many adjustments and calibrations were considered during the various stages of the construction. It is worth noting that this device has gone through many changes and/or modifications until arriving at the final present state. The concept of calculating the torque is achieved by reading the applied force from the load cell, then multiplying this force by the length of torque arm. The load cell force is transmitted through the torque arm that is in direct contact with load cell. The encoder was set up to evaluating the reciprocating angle. Encoder, Figure 1-a, is a kind of photoelectric sensor, of type CVW2-10-2MH, Romuon co., used to detect the movement and displacement of machinery parts which is used to measure the cyclic angle of twist. An inventor was responsible to control the motor speed, through a regulator that can be recognized the external source voltage. The speed has been divided into four readings i.e. the motor can run at $(375,750,1125, \& 1400 \mathrm{rpm}$ respectively). The information that feeded to the inverter is a small voltage from the Labjack U3 device, Figure 1-b, each magnitude of the small voltage make the inverter to give a suitable voltage to the motor. More details about the rig can be found in Ref [11]. The furnace temperature is controlled by a panel which cut off the power to the elements when the thermocouple measured the desired temperature inside the furnace.

When a material exposure to a completely reverse cyclic applied strain for a period of time, it shows a stress-strain behavior similar as in the static stress-strain behavior where the stress was going to increase, in liner proportional for elastic region, then reach to a maximum value (ultimate value) and going to decrease till fracture[11].The tests were conducted using the constructed rig at room temperature and $250^{\circ} \mathrm{C}$. The maximum torque was taken in to consideration in this study. All tests conditions ware at a frequency of $375 \mathrm{rpm}$ and temperature of $250^{\circ} \mathrm{C}$. A brass material was selected with the dimensional geometry as shown in Figure 2. A thin-walled tube specimen, which was machined according to ASTM 2207-2, with an overall length of $80 \mathrm{~mm}$, uniform gage section length of $16 \mathrm{~mm}$, an inside diameter of $5 \mathrm{~mm}$, and a wall thickness of $1.5 \mathrm{~mm}$. The mechanical properties obtained using the universal tensile test machine and listed in the Table 2, at room temperature while the shear modulus at $250^{\circ} \mathrm{C}$ has been interpolated using the data given in Ref[12].

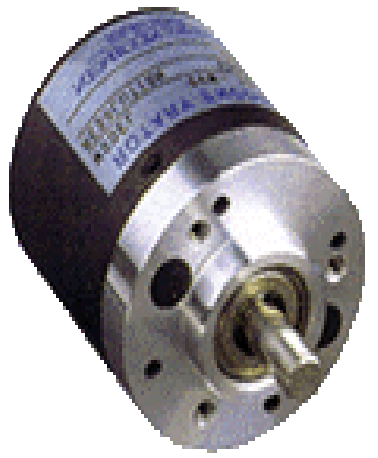

(a)

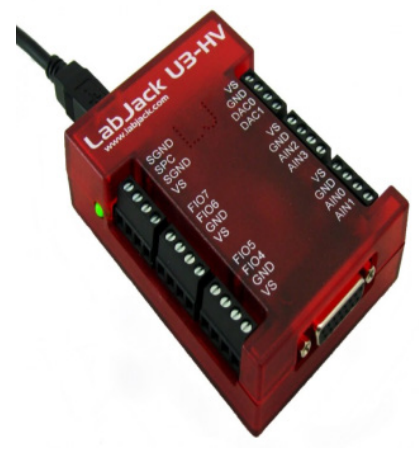

(b)
Figure 1. (a) ROMUON Encoder device, (b) The Labjack U3-HV

The fatigue test was conducted for a fifty five specimens that has been divided into a five coupons each consist of five specimens, where the applied shear strain amplitude was changed for each coupon as $(0.146,0.122,0.113,0.096$, $0.059)$ which is a condition of test.

The empirical equation (Coffin-Manson) that relates the shear strain amplitude with the number of cycles to failure has been carried out using the best fit equation for the recorded data during the test. The fatigue cyclic coefficients were found from the constants of this best fit equation [1].

The coefficients of the Ramberg-Osgood equation below were found by substituting the fatigue cyclic coefficients in the relations given by McClaflin and Fatemi [13]:

$$
\gamma_{a}=\frac{\tau_{a}}{G}+\left(\frac{\tau_{a}}{k_{o}^{\prime}}\right)^{\left(1 / n_{o}^{\prime}\right)}
$$

where, $\left(\mathrm{k}_{\mathrm{o}}^{\prime}\right)$ and $\left(\mathrm{n}_{\mathrm{o}}^{\prime}\right)$ are the cyclic strength and strain hardening respectively.

The above equation can be used to estimate the corresponding of shear stress amplitudes by substituting the applied shear strain amplitudes for each test, and with the recorded cyclic torque, the empirical equation was found to predict the value of the shear stress amplitude for each value of the maximum torque that exposure to the material. The empirical equation given as:

$$
\tau_{a}\left(T_{\max }\right)^{v}=C
$$

where $\tau_{a}$ is the shear stress amplitude, $T_{\max }$ is the maximum torque exposed to the material, and the remaining two quantities are material related constants that are obtained by experimental strain life data.

Table 1. Chemical composition of Brass alloy (wt\%)

\begin{tabular}{|c|c|c|c|c|c|c|}
\hline $\mathrm{Cu}$ & $\mathrm{Pb}$ & $\mathrm{Fe}$ & $\mathrm{Sn}$ & $\mathrm{Ni}$ & $\mathrm{Al}$ & $\mathrm{Zn}$ \\
\hline 55.2 & 2.96 & 0.78 & 1.06 & 0.23 & 0.55 & bal \\
\hline
\end{tabular}



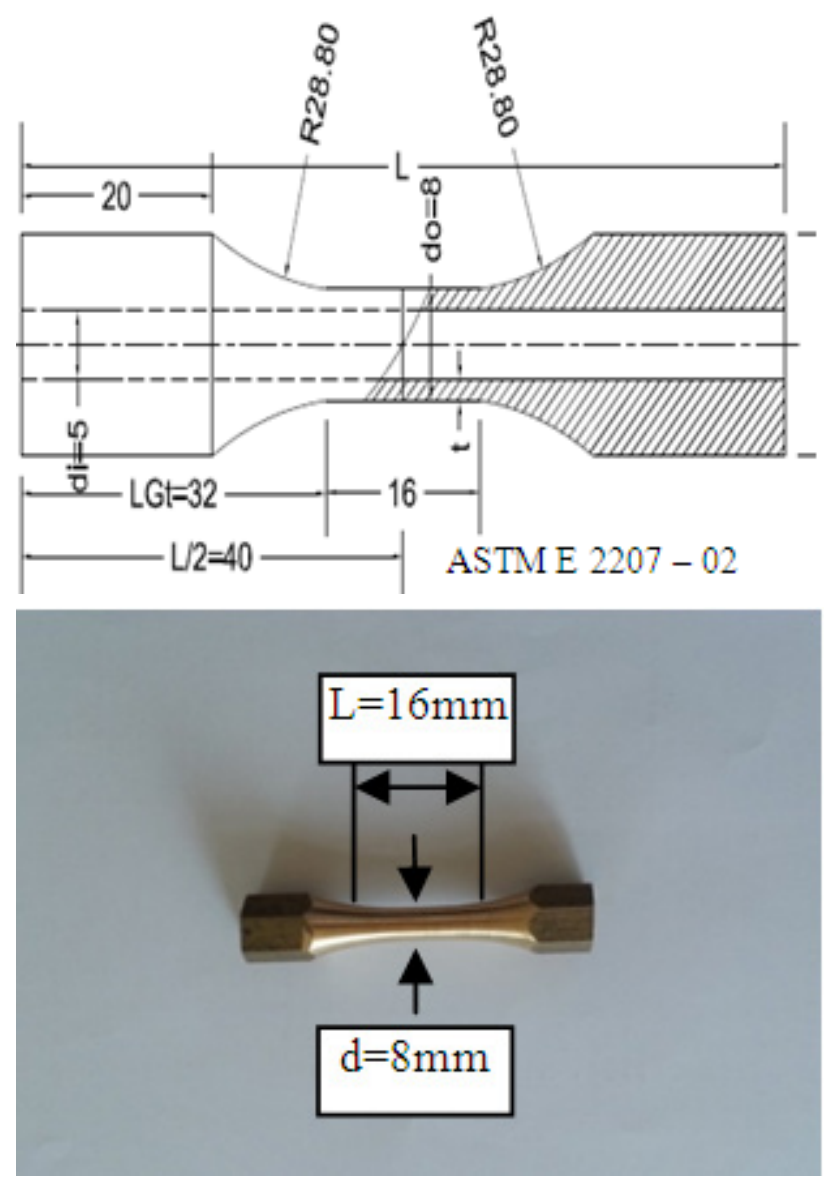

Figure 2. Geometry of the fatigue specimen

Table 2. The mechanical properties for the tested material

\begin{tabular}{|c|c|c|c|c|}
\hline $\begin{array}{c}\text { Yield } \\
\text { strength } \\
(\mathrm{MPa})\end{array}$ & $\begin{array}{c}\text { Ultimate } \\
\text { strength } \\
(\mathrm{MPa})\end{array}$ & Hardness & $\begin{array}{c}\text { Elastic } \\
\text { modulus } \\
(\mathrm{GPa})\end{array}$ & $\begin{array}{c}\text { Shear modulus (MPa), } \\
\text { at 250 }\end{array}$ \\
\hline 410 & 440 & 135 & 110 & 19.5 \\
\hline
\end{tabular}

\section{Results and Discussion}

Table 3 shows the recorded data for the torsional fatigue test based on strain at $250^{\circ} \mathrm{C}$ and for five coupons of Brass specimens with a completely reversed cyclic shear strain. The completely reversed shear strain was achieved by ensuring the specimen fixed into the grips with a zero angle level. That makes the mean angle of twist as zero. An encoder obtains the torsion angle and the torque is measured by a load cell. The recorded torque was the maximum value subjected to the specimen throughout the test when a completely reversed cyclic strain was applied since the torque varied during the test as mentioned previously. The temperature was controlled to the desired and the test started when the temperature controller read the desired. The number of cycles to failure increased when the applied cyclic shear strain amplitude decreased and the torque that applied to the material became lower [11]. Its mean that the material life which subjected to lower shear stress was higher than that subjected to higher shear stress.
The total shear strain amplitude versus number of cycles to failure plot is shown in Figure 3. This plot displays the shear strain-life curve, as well as the elastic shear strain-life and the plastic shear strain-life portions. The best fit equation between the applied shear strain and the number of the cycles to failure, for the data given in the Table 3 , has been found which has a constants refer to the fatigue cyclic coefficients (Shear fatigue strength coefficient, Shear fatigue ductility coefficient, Fatigue strength exponent, and Fatigue ductility exponent). The continuous line shown in the Figure 3 represent to the best fit equation. By compare the best fit equation with the empirical Coffin-Manson equation, a summary of the cyclic torsion properties of the material is also provided in Table 4.

Table 3. The fatigue test data records for Brass at $250^{\circ} \mathrm{C}$

\begin{tabular}{|c|c|c|}
\hline $\begin{array}{c}\text { Applied shear strain } \\
\text { amplitude }\end{array}$ & $\begin{array}{c}\text { Maximum recorded } \\
\text { torque (N.M) }\end{array}$ & $\begin{array}{c}\text { Number of } \\
\text { cycles to failure }\end{array}$ \\
\hline 0.14606 & 53.46 & 1843.750 \\
\hline 0.12208 & 46.20 & 2761.375 \\
\hline 0.11336 & 44.99 & 4253.250 \\
\hline 0.09592 & 44.00 & 4398.540 \\
\hline 0.05886 & 36.96 & 12500.000 \\
\hline
\end{tabular}

Table 4. Cyclic fatigue coefficients for brass at $250^{\circ} \mathrm{C}$

\begin{tabular}{|c|c|c|c|}
\hline $\begin{array}{c}\text { Shear fatigue strength } \\
\text { coefficient (MPa) }\end{array}$ & $\begin{array}{c}\text { Shear } \\
\text { fatigue } \\
\text { ductility } \\
\text { coefficient }\end{array}$ & $\begin{array}{c}\text { Fatigue } \\
\text { strength } \\
\text { exponent }\end{array}$ & $\begin{array}{c}\text { Fatigue } \\
\text { ductility } \\
\text { exponent }\end{array}$ \\
\hline 2000 & 6.3155 & -0.22 & -0.4737 \\
\hline
\end{tabular}

By using the fatigue cyclic coefficients and the relations given by McClaflin and Fatemi [13], the coefficients of the Ramberg-Osgood equation, (1), were found. Table 5 below shows the calculated shear stress-strain factors in a range of the shear strain.

Table 5. The cyclic strength and strain hardening respectively for Brass at $250^{\circ} \mathrm{C}$ (The coefficients of the Ramberg-Osgood equation)

\begin{tabular}{|c|c|}
\hline $\mathrm{k}_{\mathrm{o}}^{\prime}(\mathrm{MPa})$ & $\mathrm{n}_{\mathrm{o}}^{\prime}$ \\
\hline 850 & 0.464 \\
\hline
\end{tabular}

The shear stresses amplitude was estimated by substituting the applied shear strains amplitude, which listed in Table 3, in Ramberg-Osgood equation, (1). The calculated values of the shear stress and the corresponding values for the measured applied torque are the most important factors here. The empirical equation related between the shear and maximum torque has been found from the best fit for the data in Figure 4, given as:

$$
\tau_{a}\left(T_{\max }\right)^{-1.17652}=3.372
$$

Figure 4 shows the relationship between the shear stress that estimated from Ramberg-Osgood equation and the recorded maximum torque (denoted in the figure as experimental shear stress amplitude). It is clearly illustrate that the value of the shear stress has been increased when the 
applied torque on the material increased. Equation (3) is a predicted equation in plastic region since the torque that subjected on the material case a shear stress higher than the yield strength. To examine the empirical equation, it was plotted in the Figure 4 (denoted in the figure as predicted shear strain amplitude).

The mechanisms of crack growth for materials experiencing low-cycle fatigue are similar to the crack growth of a material subjected to a constant stress [14]. The deformation exhibited by a material subjected to low-cycle fatigue is typically plastic. Since the plastic strains in low-cycle fatigue are usually greater than in high-cycle fatigue because of the stress applied is higher than the yield stress for material which lead to the surface defects of the material are not as important as the bulk material properties [15].

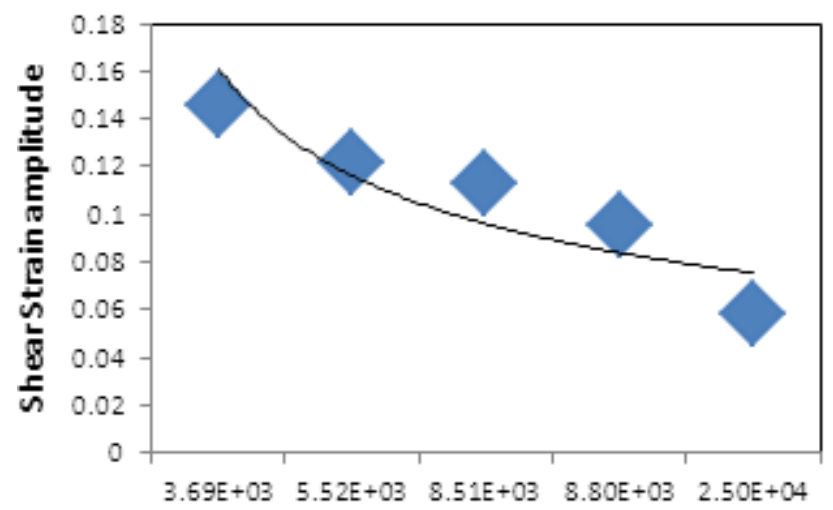

Number of cycles to failure, $2 \mathrm{~N}$

Figure 3. Shear strain amplitude versus the number of cycles to failure

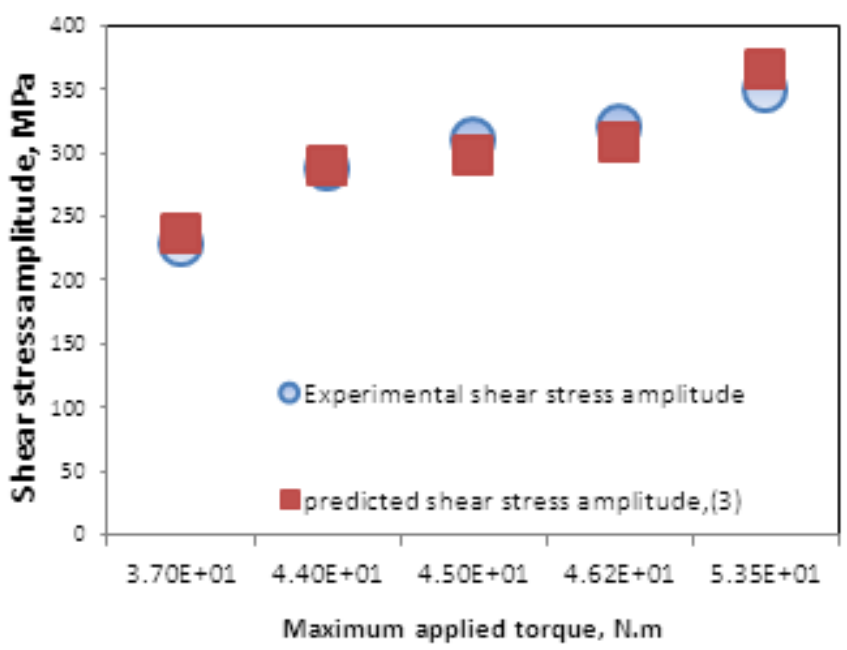

Figure 4. Predicted shear stress with the maximum applied torque

To investigate the effect of the temperature on the direct fatigue strength, it is needed to calculate the direct fatigue strength for the Brass at frequency of $375 \mathrm{rpm}$ and at temperature of $250^{\circ} \mathrm{C}$ by taken $\mathrm{N}=10^{7}$ where the corresponding shear strain value was found of 0.0046 from the extrapolation of the data in the Table 3 . The shear fatigue strength value has been found of $70 \mathrm{MPa}$ by substituting the value of the shear strain in (1) with the coefficients of Table 5 (The cyclic strength and strain hardening respectively for Brass at $250^{\circ} \mathrm{C}$ ).

Fatemi and Shamsari [16] used a model to found the corresponding values of direct fatigue stress from the shear fatigue stress that applied here to found the corresponding direct fatigue strength of $121.5 \mathrm{MPa}$.

The direct fatigue strength for Brass was found at room temperature of $220 \mathrm{MPa}$ [17]. By compare the two values it was clearly found the effect of the temperature on the fatigue strength of the brass that reduced when the temperature increased.

\section{Conclusions}

The following conclusions have been drawn basing on the performed study:

1- An empirical relationship that relate the maximum applied torque ( which can be easily measured by a sensors) with the shear stress has been found to predicted the magnitude of the shear stress that cause from exposure the material to a cyclic shear strain.

2- The empirical equation that found (3), clearly shown the calculated shear stress decreased as the applied torque decreased.

3- The temperature effect on the fatigue strength for brass caused to reduce the value comparing with the fatigue strength of the brass at room temperature.

\section{REFERENCES}

[1] Chen, C.K., Lin, C.Y. Failure analysis of brass rotor bars, Engineering Failure Analysis volume 8, 293-301, 2001.

[2] L.E. Tucker. A Procedure for Designing Against Fatigue Failure of Notched Parts, Society of Automotive Engineers, Inc., 1972.

[3] S. Mroziński \& S. Dymski. Fatigue damage cumulation in brass under variable loading, Archives of Foundry Engineering, Volume 9. 2009.

[4] Ridha Mnif, Mohamed Kchaou, Riadh Elleuch, Foued Halouani. Cyclic Behavior and Damage Analysis of Brass under Cyclic Torsional Loading, J Fail. Anal. and Preven, 2007.

[5] J. D. Bressan \& R. K. Unfer. Construction and validation tests of a torsion test machine, J. Materials Processing Technology, No.179, 2006.

[6] M. R. Abdul Hassan. Microstructure and hardness effects on behavior of copper alloy under creep-fatigue interaction, Eng. \& Tech. Journal, vol.29, No.9, 2011.

[7] Ahmad Fitri. Endurance limit of Aluminum , Brass, and mild steel on different surface finish owing to cyclic loads, University Malaysia Pahang, 2009.

[8] T. Fukuda, N. Hironobu. Quantitative Measurement of 
Micro-Deformation of Electropolished Carbon Steel Using an Image Processing Technique, International Journal of Modern Physics, Volume 17, Issue 08, 10 April 2003.

[9] N. Gao, M. W. Brown, K.J. Miller," Fatigue Fracture", J. Engineering Materials Structure, 1995.

[10] T. Beck, B. Denne, K. H. Lang, D. L. He. A Torsional Fatigue Testing Machine Based on a Commercial AC Servo- Actuator, Material prüfung, ISSN: 0025-5300, 2001.

[11] A. D. Hassan. Experimental and theoretical study of AISI 316L stainless steel behavior under creep-fatigue interaction, P.hd. Thesis, university of Basrah, 2013.

[12] Materials Data Book, Cambridge University Engineering Department, Edition 2003.
[13] D. McClaflin, A. Fatemi. Torsional deformation and fatigue of hardened steel including mean stress and stress gradient effects, International Journal of Fatigue, Volume 26, 2001.

[14] A. Fatemi., N. Shamsari. An overview and some approximation models for life estimation, International Journal of Fatigue, vol. 61, January 2011.

[15] B. D. Craig, Material Failure Modes. Advanced materials and processes technology, Volume 9, Number 1, Rome, 2000.

[16] A. Fatemi, N. Shamsari. An overview and some approximation models for life estimation, International Journal of Fatigue, vol. 61, January 2011.

[17] Donald R Askeland. The Science and Engineering of Materials, Published by Chapman and Hall ISBN 041234260 X,2011. 